\title{
THE OPTIMIZATION OF THE RELIABILITY AND CONSTRUCTION COST OF RC BRIDGES
}

\author{
Wen-Hu Tsao \\ Associate Professor, Department of Civil Engineering, China Institute of Technology, Taipei, Taiwan, R.O.C, \\ tsaowh@cc.chit.edu.tw \\ Chi-Way Lin \\ Graduate student, Department of Harbor and River Engineering, National Taiwan Ocean University, Keelung, Taiwan, \\ R.O.C \\ Ming-Te Liang \\ Professor, Department of Civil Engineering, China Institute of Technology, Taipei, Taiwan, R.O.C. \\ Wen-Lung Wen-Lung Tsao Tsao \\ Instructor, Department of Civil Engineering, China Institute of Technology, Taipei, Taiwan, R.O.C
}

Follow this and additional works at: https://jmstt.ntou.edu.tw/journal

Part of the Civil and Environmental Engineering Commons

\section{Recommended Citation}

Tsao, Wen-Hu; Lin, Chi-Way; Liang, Ming-Te; and Tsao, Wen-Lung Wen-Lung Tsao (2005) "THE OPTIMIZATION OF THE RELIABILITY AND CONSTRUCTION COST OF RC BRIDGES," Journal of Marine Science and Technology. Vol. 13: Iss. 4, Article 5.

DOI: $10.51400 / 2709-6998.2121$

Available at: https://jmstt.ntou.edu.tw/journal/vol13/iss4/5

This Research Article is brought to you for free and open access by Journal of Marine Science and Technology. It has been accepted for inclusion in Journal of Marine Science and Technology by an authorized editor of Journal of Marine Science and Technology. 


\title{
THE OPTIMIZATION OF THE RELIABILITY AND CONSTRUCTION COST OF RC BRIDGES
}

\author{
Wen-Hu Tsao*, Chi-Way Lin**, Ming-Te Liang***, and Wen-Lung Tsao****
}

Key words: DER evaluation method, failure loss, optimum reliability, engineering system construction cost.

\begin{abstract}
In this paper, the relationship between reliability and engineering system construction cost for obtaining optimum reliability was studied. This proposed approach was applied to the repair alternatives of existing reinforced concrete (RC) bridges for acquiring the result of optimization analysis. According to the $\mathrm{D}$ (degree) $\mathrm{E}$ (extent) $\mathrm{R}$ (relevancy) evaluation method, which is widely used by civil engineers in Taiwan the existing RC bridges with and without stridden rivers can be divided into 21 and 17 substructures, respectively. The use of the weighting value and the cost relation is to attain the relationship between the total engineering system construction cost and the reliability of the existing RC bridges. The combination of the reliability and construction cost with the structural failure cost obtained from the expected cost is to gain the optimum reliability of the existing RC bridges. Moreover, the optimization repair alternative and the service life of the existing RC bridges are thus obtained. The result of present study shows that the more the cost of the RC bridge maintenance is, the more the whole profit of the weighting influence has. The failure loss cost also influences the optimum reliability. The present study results may offer the decision-making of the repair, strengthening, and demolition for the existing RC bridges.
\end{abstract}

\section{INTRODUCTION}

Bridges are one of the most important transportation facilities in developed countries. The design and construction of a most durable, economical and esthetic bridge become an important topic for research. In recent years, insufficient maintenance causes bridge degradation, which is responsible for frequent collapses. Some maintaining and repairing expenses have already

Paper Submitted 07/14/04, Accepted 06/28/05. Author for Correspondence: Wen-Hu Tsao.E-mail: tsaowh@cc.chit.edu.tw.

*Associate Professor, Department of Civil Engineering, China Institute of Technology, Taipei, Taiwan, R.O.C.

**Graduate student, Department of Harbor and River Engineering, National Taiwan Ocean University, Keelung, Taiwan, R.O.C.

***Professor, Department of Civil Engineering, China Institute of Technology, Taipei, Taiwan, R.O.C.

****Instructor, Department of Civil Engineering, China Institute of Technology, Taipei, Taiwan, R.O.C. exceeded the initial construction cost. Thus, it is further necessary to study the relationship between engineering system construction cost and optimum reliability.

There are a lot of evaluation methods for the construction and maintenance cost of bridges. Mohammadi and Guralnick [13] and Frangopl and Furuta [5] used simple and easy cash flow to calculate the whole construction cost of service life cycle and offered the policy to make the most economical design plan. Al-Hajj [1] found the forty percent from the initial construction cost and the sixty percent from the maintenance and discard cost for bridge in the service life cycle in Britain. Frangopol [4] and Wang [18] pointed out that if one of the substructures becomes invalid, then the whole structure fails. The relationship between the reliability and the system construction cost can be obtained from each substructure. Cheung and Kyle [2] used the reliability to analyze the service life cycle of concrete structures. Moses [14] proposed the reliability of stress from the major structure to evaluate the optimum scheme. Sexsmitha and Reidb [15] proposed the failure loss cost, which is quite significant. Imai and Frangopol [6] presented the estimation of non-linear elastic structure analysis of suspension bridge. Liang and Lan [10] used the method of reliability analysis to predict the structural system joint failure probability at different service times for existing RC wharves under the combination of chloride environment and load bearing. Liang and Lan [11] investigated the failure probability for existing RC pile corrosion due to carbonation, chloride on ingress and sulfate attach combined with load-carrying capacity for bridge substructures at different amounts of service times. However, the relationship between the optimum reliability and the engineering system construction cost has not been investigated until now. This is a noticeable shortcoming, because the study of relationship between reliability and construction cost is of utmost importance.

The main purpose of this research is to predict the optimization of the reliability and the engineering system construction cost for reinforced concrete RC bridges. One stridden-river and another non-stridden 
river RC bridges were given as two illustrative examples to demonstrate the optimum reliability and the most economic maintenance expenses. The result of present study provides the practical example of decision-making of structural repair, strengthening, and demolition of existing $\mathrm{RC}$ bridges from an engineering point of view.

\section{RELATIONSHIP BETWEEN ENGINEERING SYSTEM CONSTRUCTION COST AND RELIABILITY}

In the engineering system, any one of the substructure failure may affect the whole system. To avoid the structural failure, the structural reliability should be increased. However, the reliability is proportional to the construction cost. To increase the reliability, the requirement of the construction cost will definitely grow. On the premise of considering both the recent investment (construction cost) and the long-term economic profit (failure expectation), the choice for the structural optimum reliability is an important topic. Thus, the maximum economic profit can be obtained.

For finding the maximum economic profit, i.e., finding an optimization value under the maximum reliability and the minimum construction cost, the lowest construction cost after determining the reliability can be expressed as Wang [19].

$$
\left.\begin{array}{l}
C=\sum_{j=1}^{J} C_{j}\left(\varphi_{j}\right) \rightarrow \min \\
\text { Satisfy } \prod_{j=1}^{J} \varphi_{j}=\varphi\left(\varphi_{j} \in[0,1]\right)
\end{array}\right\}
$$

where $C$ is the total construction cost, $C_{j}$ is the construction cost of the $\mathrm{j}^{\text {th }}$ year, $\varphi$ is the total reliability, and $\varphi_{j}$ is the reliability of the $\mathrm{j}^{\text {th }}$ year. $\sum_{j=1}^{J} C_{j}\left(\varphi_{j}\right)$ is the sum of $J$ terms $C_{1}\left(\varphi_{1}\right), C_{2}\left(\varphi_{2}\right), \ldots$, and $C_{J}\left(\varphi_{J}\right)$, in which $J$ is the index of summation, $C_{j}$ is the $\mathrm{j}^{\text {th }}$ term of the sum, and the upper and lower bounds of summation are $J$ and 1 , In the same manner, $\prod_{j=1}^{J} \varphi_{j}$ is the product of $J$ terms $\varphi_{1}, \varphi_{2}, \ldots$,
and $\varphi_{j}$.

The optimum reliability under the total construction cost limit can be expressed as

$$
\left.\begin{array}{c}
\varphi=\prod_{j=1}^{J} \varphi_{j} \rightarrow \max \\
\text { Satisfy } \sum_{j=1}^{J} C_{j}\left(\varphi_{j}\right)=C
\end{array}\right\}
$$

The reliability of the engineering structure is de- fined as the probability that can work normally under scheduled working condition. It's not only for the safety index, but also for the budget of the construction cost. It can look after both the investment at present and the benefit for the long term. The design of optimum reliability, $\varphi$, should be a reasonable design model. Considering the condition under the recent investigation and long-term social and economic profit, the optimum reliability can be described as

Find $\varphi \in[0,1]$ Let objective function

$$
W(\varphi)=C(\varphi)+(1-\varphi) D \rightarrow \min
$$

where $W(\varphi)$ is the total cost, $C(\varphi)$ is the construction cost of structure, $\varphi$ is the reliability of structure, $(1-\varphi)$ is the failure probability [19] of structure, $D$ is the economic loss due to structural failure, and $(1-\varphi) D$ is the expected values of above losses.

Eq. (3) represents an optimum reliability problem that find a function with a single variable $\varphi$ subjected to minimum values if the values of function $C(\varphi)$ and $D$ are given, then the optimum reliability $\varphi^{*}$ can be solved immediately as seen in Figure 1. The value of $D$ in Eq. (3) represents the economic loss due to the structural failure. It is simply called "failure loss". It is adopted for a failure criterion in the reliability analysis, i.e., the prescribed limit state. Now, we mention it as follows: (1) Normal use limit state: In this state, we should confront the deformation, vibration, and local failure due to prompt occurrence and influenced normal use or can not satisfy the other particular requirements. This failure brings the failure loss, $D$, is equivalent to the requirement cost of local rehabilitation, strengthening, and reinforcement.

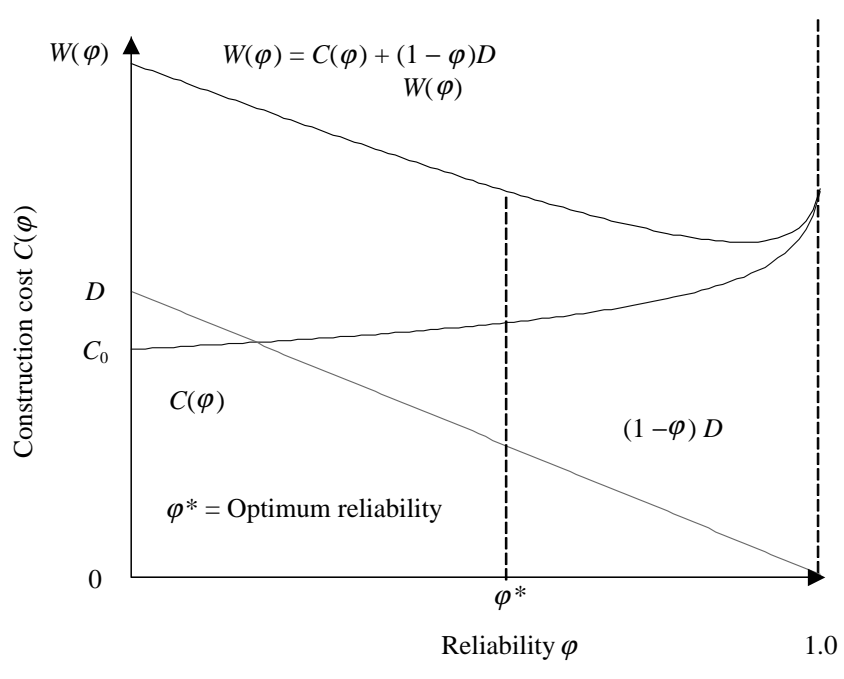

Fig. 1. Relationship between optimum reliability and construction cost. 
(2) Bearing capacity limit state: In this state, the structure will cause a local strength failure. The residual deformation of the structure is too large. The structure loses its stability and transfers as a mobile system, This failure brings the failure loss, $D$, included in the economic loss, which is due to the suspending work in addition to the local rehabilitation and the strengthening cost.

(3) Failure safe limit state: In this state, the structure will suffer severe failure (i.e., useless for rehabilitation) and collapse. This injures the safe of human body and brings a lot of disasters. This failure brings the failure loss, $D$, consisted of the economic loss due to completely stopped production, the whole structural value, the demolition cost of local structure, the second disaster, personal casualties, and the other political losses.

The evaluation method of the structural failure loss will need a professional evaluation, and the actual value cannot be easily sought.

The relationship between the reliability and the construction cost has been established. If given the experience curves or the evaluation method of failure loss $D$ and the expression of $C(\varphi)$, then the optimum economic reliability can be caught. Hence, they can be found by using the following expressions in the form [19]. (see Appendix A)

$$
\begin{aligned}
& \varphi_{j}\left(C_{j}\right)=1-e^{-w_{j}\left(C_{j} / C_{0 j}-1\right)} \\
& C_{j}\left(\varphi_{j}\right)=\left[1-\frac{1}{w_{j}} \ln \left(1-\varphi_{j}\right)\right] C_{0 j}
\end{aligned}
$$

where $C_{0 j}$ is the construction cost of the first year.

In this paper, the approximate formula of the optimum economic reliability, $\varphi$, can be obtained by the relationship between the construction cost, $C$, and the reliability, $\varphi$, and can be expressed in terms of (see Appendex A)

$$
\begin{aligned}
& \varphi(C)=1-e^{-w\left(C / C_{0 j}-1\right)} \\
& w=\frac{w_{1}}{C_{01} \xi} \sum_{j=1}^{J} C_{0 j}+\ln \frac{\xi}{\theta}
\end{aligned}
$$

where $w_{1}$ is the first item of $w_{j}, C_{0}=\frac{C_{01} \xi}{w_{1}}, \frac{w_{1}}{C_{01}}=$ $\min _{j=1}^{J}\left(\frac{w_{j}}{C_{0 j}}\right)$, in which $w_{j}$ is the weighting value of the $\mathrm{j}^{\text {th }}$ item, $\xi=\sum_{j=1}^{J} w_{j 1}, \quad \theta=\left(\prod_{j=1}^{J} w_{j 1}{ }^{w_{j 1}}\right)^{1 / \xi}$, and $w_{j 1}=\frac{w_{1}}{C_{01}}$ $/ \frac{w_{1}}{C_{0 j}}$.

Eq. (6) can be rewritten as

$$
C(\varphi)=\left[1-\frac{1}{w} \ln (1-\varphi)\right] C_{0}
$$

Substituting the initial construction cost $C_{0}$ and $w$ into Eq. (7), we obtain the relationship between reliability, $\varphi$, and the construction $\operatorname{cost}, C$. If given the assessment method of failure loss, $D$, then the optimum reliability, $\varphi^{*}$, can be found.

The failure loss, $D$, is the inverse ratio of the highest expected profit value. The failure loss increases when the highest expected profit decreases. When setting the highest expected profit as zero, the maximum failure loss will be obtained. Using this idea, the failure loss after $t$ years can be simplified by

$$
D=C_{0}\left(1+h_{j}\right)^{t}
$$

where $h_{j}$ is the annual expected profit.

It is worthy to point out that the optimization economic reliability can be obtained by choosing the maximum of the summation of construction cost, $C(\varphi)$, and the failure probability, $(1-\varphi) D$.

\section{THE OPTIMIZATION ANALYSIS OF REPAIR ALTERNATIVE}

Whether a RC bridge needs to be repaired or not is always a very difficult problem to be determined. Repair time, degree, cost, and subsequent economic effect cannot be usually obtained for the correct result. The repair problem indeed includes many variables. Some variables will change with time, while others become severe problems due to unexpected event. Regarding these problems, the analysis and decision can be described as follows:

\section{Repair strategy with preventability}

Van and Liou [17] proposed the annual net profit of bridge at original construction

$$
A(n)=\left[\sum_{i=1}^{n} \frac{J_{i}}{(1+r)^{i}}+\frac{L_{n}}{(1+r)^{n}}-C_{0}\right](A / P, r, n)
$$

where $A(n)$ is the annual net profit, $r$ is the capital profit, $J_{i}$ is the economic profit per year, $L_{n}$ is the residual value after $n$ years, $C_{0}$ is the investment cost, and $(A / P, r, n)$ is the conversion coeffieient of the annual net profit., $A$, and present value, $P$, i.e., it can be expressed as $[7,16]$

$$
A=P\left[\frac{r(1+r)^{n}}{(1+r)^{n}-1}\right]
$$

Substituting the reliability, $\varphi$, maintenance cost, 
$E$, and failure loss, $D$, into Eq. (9), we have

$$
\begin{aligned}
W\left(\varphi_{1}^{\prime}\right) & =\left(\sum_{i=1}^{t_{r}}\left(\frac{J_{i}-E_{i}}{(1+r)^{i}}\right)-\left(\frac{D}{(1+r)^{t_{r}}}\right)\right)\left(\varphi_{1}^{\prime}-\varphi_{1}\right) \\
& -C_{r}\left(\varphi_{1}^{\prime}\right) \rightarrow \max
\end{aligned}
$$

where $\varphi_{1}^{\prime}$ is the reliability of working normally after invested repair cost, $C_{r}, \varphi_{1}$ is the reliability of working normally without repair, $t_{r}$ is the years of working normally, and $E_{i}$ is the annual maintenance cost. (The value of $J$ can be estimated by manager. $E$ can be approximated as a constant.)

Owing to the optimization economic reliability of $\mathrm{RC}$ bridge has been found, this value can be used to obtain the maximum economic profit whether or not repair is needed. The reliability of a RC bridge gradually decreases every year after $t$ years. If the expected event has not happened, then the reliability can be defined as

$$
\varphi_{1}=\varphi_{1}^{\prime}-t_{1} p
$$

where $\varphi_{1}^{\prime}$ is the reliability of working normally after invested repair cost $C_{r}$ and passed $t_{1}$ years, $\varphi_{1}$ is the reliability of working normally when accomplished construction without repair, and $P$ is the reliability reduced per year.

Substituting Eq. (12) into Eq. (11), we have [8]

$$
\begin{aligned}
W\left(\varphi_{1}^{\prime}\right) & =\left(\sum_{i=1}^{t_{r}}\left(\frac{J_{i}-E_{i}}{(1+r)^{i}}\right)-\left(\frac{D}{(1+r)^{t_{r}}}\right)\right)\left(t_{1} p\right) \\
& -C_{r}\left(\varphi_{1}^{\prime}\right) \rightarrow \max
\end{aligned}
$$

If the evaluation expression obtained from the given $D$ value and the economic profit brought every year and using the finding optimization economic reliability, then we can ascertain the optimum economic effect after repair.

\section{Rehabilitation strategy after calamity}

While making strengthening and repairing planning after calamity, if satisfy the repair criterion in terms of [18]

$$
J T_{1} \varphi_{1}^{\prime}>C_{r}\left(\varphi_{1}^{\prime}\right)+\left(1-\varphi_{1}^{\prime}\right) D
$$

then the RC bridge can be carried out for rehabilitation. The reliability with optimization repair can be obtained as planned by

$$
J T_{1} \varphi_{1}^{\prime}-C_{r}\left(\varphi_{1}^{\prime}\right)-\left(1-\varphi_{1}^{\prime}\right) D \rightarrow \max
$$

If compare the optimization repair reliability, $\varphi_{1}$, with the real structural reliability, $\varphi\left(t_{1}^{\prime}, T_{1}\right)$, considered the reliability with optimum economic design and repair, then the predicted results are different.

\section{ILLUSTRATIVE EXAMPLES}

Example 1:

In the DER evaluation method $[3,9,10,11]$, a general RC bridge with stridden river can be divided into 21 substructures as sketched in Figure 2. Assume a RC bridge is of 20 meters width and 40 meters length as shown in Figure 3. Every unit cost of the RC bridge has been passed assessment. According to each substructural volume, the parameter $C_{0 j}$ (the unit is $10^{3}$ NTD (New Taiwan Dollar) can be found as listed in Table 1. From the DER evaluation method, each substructural weighting value, $w_{j}$, is denoted as in Table 2 . The relation curve between the total construction cost, $C$, and the reliability, $\varphi$, of 21 substructures of the RC bridge is tried to figure out and its optimum reliability can also be procured. After this bridge has been serviced for 30 years, the corrosion phenomenon of the reinforcing bar in concrete has happened. Assume that its reliability will be dropped by 0.02 per year. The
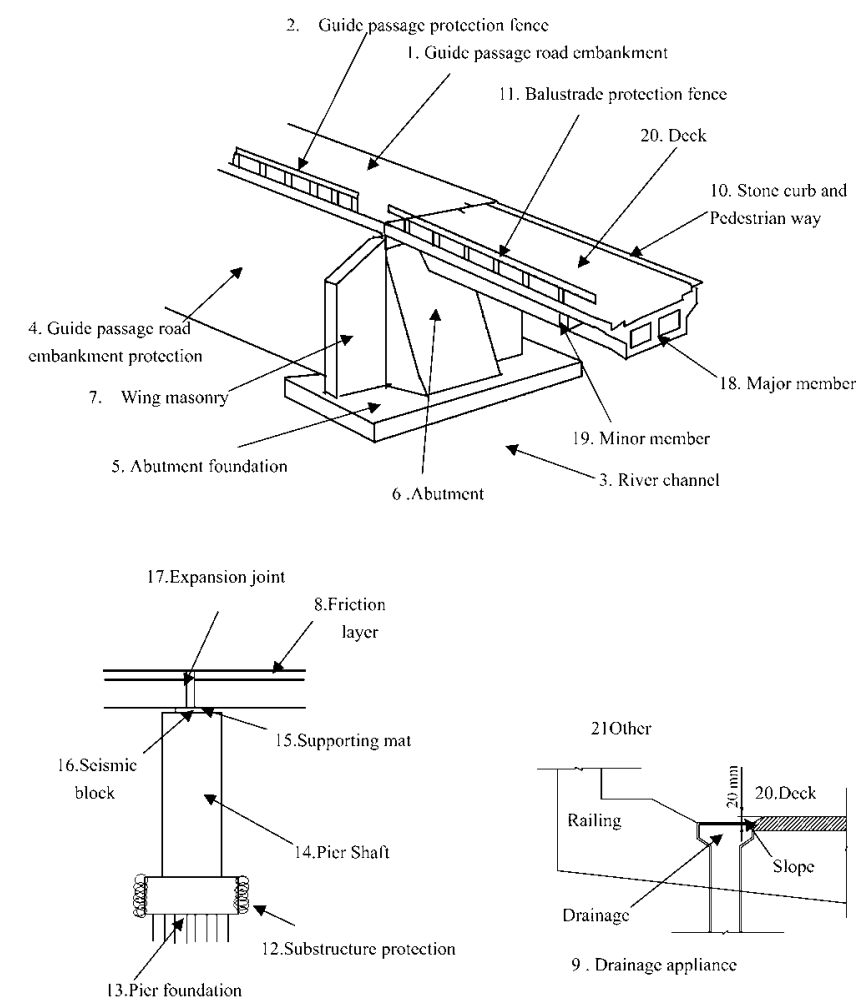

Fig. 2. Substructure of RC bridge with stridden river. 
Table 1. Construction cost of $\mathrm{RC}$ bridge with stridden river

\begin{tabular}{|c|c|c|c|c|c|}
\hline Component & $\begin{array}{c}\text { Construction } \\
\operatorname{cost}\left(\times 10^{3} \text { NTD }\right)\end{array}$ & Component & $\begin{array}{c}\text { Construction } \\
\text { cost }\left(\times 10^{3} \text { NTD }\right)\end{array}$ & Component & $\begin{array}{c}\text { Construction } \\
\text { cost }\left(\times 10^{3} \text { NTD }\right)\end{array}$ \\
\hline $\begin{array}{l}\text { 1. Guide passage } \\
\text { road embankment }\end{array}$ & 200 & 8. Friction layer & 80 & 15. Supporting mat & 110 \\
\hline $\begin{array}{l}\text { 2. Guide passage } \\
\text { protection fence }\end{array}$ & 150 & $\begin{array}{l}\text { 9. Drainage } \\
\text { appliance }\end{array}$ & 120 & 16. Seismic block & 90 \\
\hline 3. River channel & 290 & $\begin{array}{l}\text { 10. Stone curb and } \\
\text { pedestrian way }\end{array}$ & 90 & 17. Expansion joint & 60 \\
\hline $\begin{array}{l}\text { 4. Guide passage } \\
\text { road embankment } \\
\text { protection }\end{array}$ & 210 & $\begin{array}{l}\text { 11. Balustrade } \\
\text { protection fence }\end{array}$ & 100 & 18. Major member & 270 \\
\hline $\begin{array}{l}\text { 5. Abutment } \\
\text { foundation }\end{array}$ & 170 & $\begin{array}{l}\text { 12. Substructure } \\
\text { protection }\end{array}$ & 170 & 19. Minor member & 210 \\
\hline 6. Abutment & 280 & 13. Pier foundation & 220 & 20. Deck & 150 \\
\hline 7. Wing masonry & 100 & 14. Pier shaft & 190 & 21. Other & 130 \\
\hline
\end{tabular}

Table 2. Weighting values of D.E.R. evaluation method for the composite component of $\mathrm{RC}$ bridge with stridden river

\begin{tabular}{|c|c|c|c|c|c|}
\hline Component & $\begin{array}{c}\text { Weight } \\
\text { factor }(w)\end{array}$ & Component & $\begin{array}{c}\text { Weight } \\
\text { factor }(w)\end{array}$ & Component & $\begin{array}{l}\text { Weight } \\
\text { factor }(w)\end{array}$ \\
\hline $\begin{array}{l}\text { 1. Guide passage } \\
\text { road embankment }\end{array}$ & 3 & 8. Friction layer & 3 & 15. Supporting mat & 5 \\
\hline $\begin{array}{l}\text { 2. Guide passage } \\
\text { protection fence }\end{array}$ & 2 & 9. Drainage appliance & 4 & 16. Seismic block & 5 \\
\hline 3. River channel & 3 & $\begin{array}{l}\text { 10. Stone curb and } \\
\text { pedestrian way }\end{array}$ & 2 & 17. Expansion joint & 6 \\
\hline $\begin{array}{l}\text { 4. Guide passage } \\
\text { road embankment } \\
\text { protection }\end{array}$ & 3 & $\begin{array}{l}\text { 11. Balustrade } \\
\text { protection fence }\end{array}$ & 3 & 18. Major member & 8 \\
\hline 5. Abutment foundation & 7 & $\begin{array}{l}\text { 12. Substructure } \\
\text { protection }\end{array}$ & 6 & 19. Minor member & 6 \\
\hline 6. Abutment & 6 & 13. Pier foundation & 8 & 20. Deck & 7 \\
\hline 7. Wing masonry & 5 & 14. Pier shaft & 7 & 21. Other & 1 \\
\hline
\end{tabular}

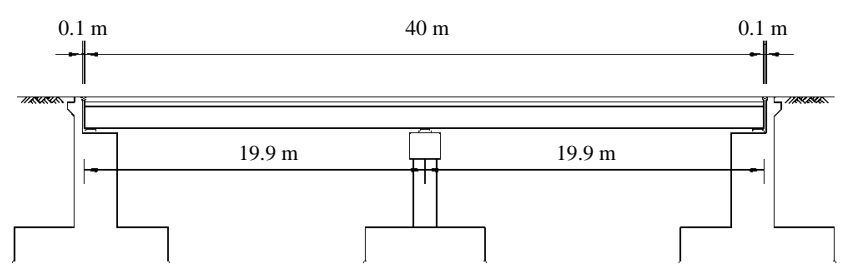

(a) Span arrangement

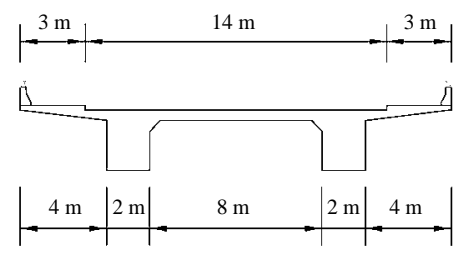

(b) Cross section

Fig. 3. RC bridge with stridden river. economic losses increase when the reliability decreases. If after maintaining it, we can receive the economic benefits of $20 \times 10^{7}$ NTD to drop by $3 \%$ per year. Assume that the repair cost is $10 \%$ of the construction cost, the maintenance expenses is $100 \times 10^{3}$ NTD per year and is $20 \%$ increasing progressively per year, the capital interest rate, $r$, is $12 \%$, and the value of failure loss, $D$, rises with $1 \%$ per year. How long will it be to get the maximum profit value after repair?

According to the proportion value of $w_{j} / C_{0 j}$ and rearranging them for the 21 substructures of $\mathrm{RC}$ bridge, and calculating each substructure's $w_{j 1}=\frac{w_{1}}{C_{01}} / \frac{w_{j}}{C_{0 j}}$, we obtain the results as shown in Table 3. According to Table 3 and Eq. (6), we have $\xi=\sum_{j=1}^{J} w_{j 1}=0.51+0.57$ $+\cdots+0.16+1=6.83 . \quad \theta=\left(\prod_{j=1}^{J} w_{j 1}{ }^{w_{j 1}}\right)^{1 / \xi}=\left(0.51^{0.51} \times\right.$ 
Table 3. Construction cost and weighting value for $\mathrm{RC}$ bridge with stridden river

\begin{tabular}{cccccccccccc}
\hline Structural member $j$ & 21 & 2 & 3 & 4 & 1 & 6 & 10 & 19 & 18 & 11 \\
$w_{j}$ & 1 & 2 & 3 & 3 & 3 & 6 & 2 & 6 & 8 & 3 \\
$C_{0 j}\left(\times 10^{3} \mathrm{NTD}\right)$ & 130 & 150 & 290 & 210 & 200 & 280 & 90 & 210 & 270 & 100 \\
$w_{j} / C_{0 j}$ & 0.0076 & 0.0133 & 0.0103 & 0.0143 & 0.0115 & 0.0214 & 0.0222 & 0.0286 & 0.0296 & 0.0300 \\
$w_{j 1}$ & 1 & 0.57 & 0.54 & 0.53 & 0.51 & 0.36 & 0.34 & 0.27 & 0.26 & 0.25 \\
\hline & & & & & & & & & & & \\
\hline Structural member $j$ & 9 & 12 & 13 & 14 & 8 & 5 & 15 & 20 & 7 & 16 & 17 \\
$w_{j}$ & 4 & 6 & 8 & 7 & 3 & 7 & 5 & 7 & 5 & 5 & 6 \\
$C_{0 j}\left(\times 10^{3} \mathrm{NTD}\right)$ & 120 & 170 & 220 & 190 & 80 & 170 & 110 & 150 & 100 & 90 & 60 \\
$w_{j} / C_{0 j}$ & 0.0333 & 0.0353 & 0.0364 & 0.0368 & 0.0375 & 0.0412 & 0.0455 & 0.0467 & 0.0500 & 0.0556 & 0.1000 \\
$w_{j 1}$ & 0.23 & 0.22 & 0.21 & 0.21 & 0.20 & 0.18 & 0.17 & 0.16 & 0.15 & 0.14 & 0.08 \\
\hline
\end{tabular}

$\left.0.57^{0.57} \times \ldots \times 0.16^{0.16} \times 1^{1}\right)^{1 / 6.83}=(0.0018)^{1 / 6.83}=0.396$,

$w=\frac{w_{1}}{C_{01} \xi} \sum_{j=1}^{J} C_{0 j}+\ln \frac{\xi}{\theta}=\frac{1}{130 \times 6.83} \times 3390+\ln \frac{6.83}{0.396}=$

$6.667, C_{0}=\frac{C_{01} \xi}{w_{1}} w=\frac{130 \times 6.83}{1} \times 6.667=5916.47(\times$

$10^{3}$ NTD).

Substituting $w$ and $C_{0}$ into Eq. (7), we have the relational expression between total system construction cost and reliability in terms of

$$
\begin{aligned}
C(\varphi) & =\left[1-\frac{1}{w} \ln (1-\varphi)\right] C_{0} \\
& =5916.47 \times[1-0.15 \ln (1-\varphi)] .
\end{aligned}
$$

Utilizing the expected profit value, $h$, we find the value of failure loss, $D$. Substituting the value of $D$ into Eq. (8), we obtain

$$
D=C_{0}(1+0.01)^{30}=7974.51
$$

Inserting the found values $(C(\varphi)$ and $D)$ into Eq. (3) and choosing its minimum, we have

$$
\begin{aligned}
W(\varphi) & =C(\varphi)+(1-\varphi) D \rightarrow \min \\
& =5916.47[1-0.15 \ln (1-\varphi)] \\
& +7974.51(1-\varphi) \rightarrow \min
\end{aligned}
$$

We can obtain the optimum reliability, $\varphi=0.89$, under optimum economy and the total construction cost, $8752.557 \times 10^{3} \mathrm{NTD}$, as displayed in Figure 4. From the total value of the construction cost and failure probability, it is very obvious that the lowest cost value is occurred under the condition of the best reliability at optimum economy.
From the topic, we know that the annual economic benefits is $J_{i}=2000(1-0.03 i)$, the maintenance cost is $E_{i}=100(1+0.2)^{i}$ per year, the repair cost is $C_{r}=$ $0.1 C_{0}$, the failure loss value is $D=7974.51$, and the annual reliability drops $p=0.02$. Substituting all these values into Eq. (13), we obtain [8]

$$
\begin{aligned}
& W\left(\varphi_{1}^{\prime}\right)=\left(\sum_{i=1}^{t_{r}}\left(\frac{J_{i}-E_{i}}{(1+r)^{i}}\right)-\frac{D}{(1+r)^{t_{r}}}\right)\left(t_{1} p\right)-C_{r}\left(\varphi_{1}^{\prime}\right) \rightarrow \max \\
& =\left(\sum_{i}^{t_{r}} \frac{2000(1-0.03 i)-100(1+0.2)^{i}}{(1+0.12)^{i}}-\frac{7974.51}{(1+0.12)^{t_{r}}}\right) \\
& (0.02 \times 30)-0.1 \times 8752.557 \times 0.89 .
\end{aligned}
$$

Choosing its maximum by using computer pack-

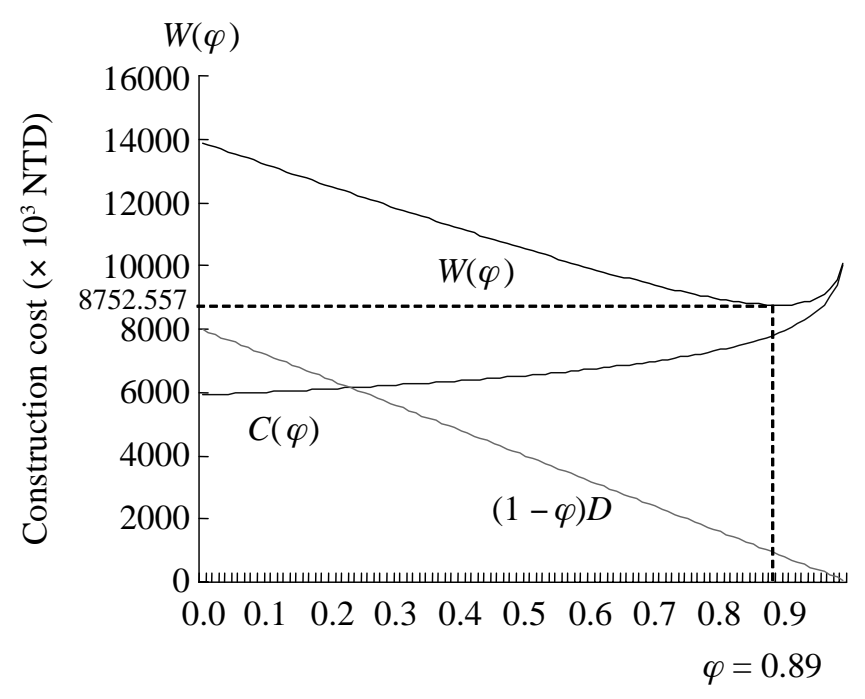

Fig. 4. Relationship between reliability and construction cost of RC bridge with stridden river after repair. 
age "Excel worksheet", we have the annual profit, $2228.91 \times 10^{3} \mathrm{NTD}$, at $t_{r}=18$ years. As seen in Figure 5 , we get the optimum profit at 18 years. In order to reach the maximum economic benefits, the decision will be made as to whether this RC bridge will be repaired or rebuilt again after 18 years.

\section{Example 2}

In the DER evaluation method, a RC bridge without stridden river can be divided into 17 substructures. Suppose a bridge is 20 meters in length and 15 meters in width as indicated in Figure 6. Every unit cost of the $\mathrm{RC}$ bridge has been passed assessment. According to each substructural volume, the parameter $C_{0 j}(\mathrm{x}$ $10^{3}$ NTD) is calculated as shown in Table 4. From the DER evaluation method, each substructural weighting

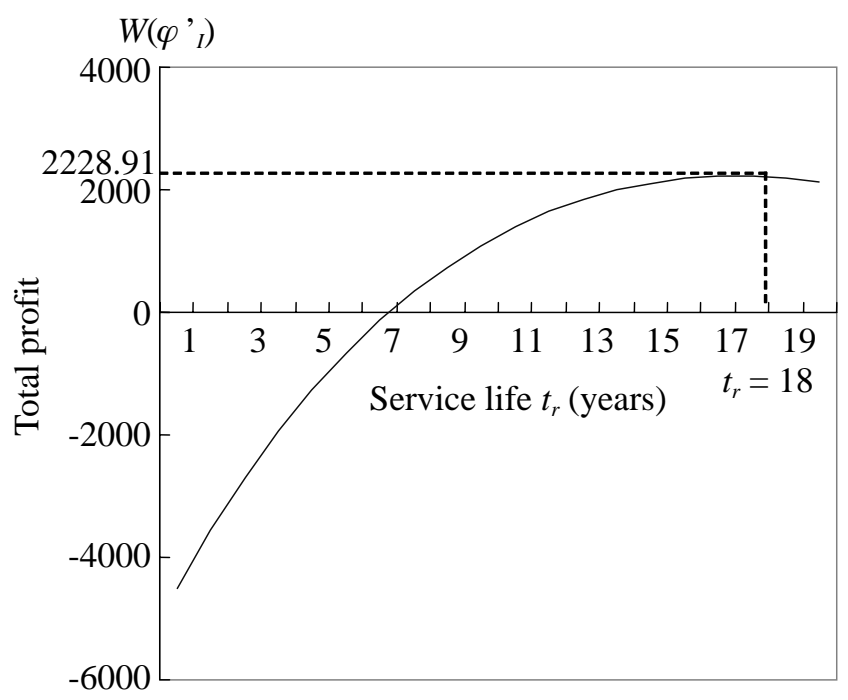

Fig. 5. Relationship between service life and total profit of $\mathrm{RC}$ bridge with stridden river after repair. value $w_{j}$ is listed in Table 5. The relation curve between the total construction $\operatorname{cost} C$ and the reliability $\varphi$ of $\mathrm{RC}$ bridge without stridden river is found and the optimum reliability of optimization economics is also obtained.

According to proportional values of $w_{j} / C_{0 j}$ and rearranging 17 substructures of $\mathrm{RC}$ bridge first, and

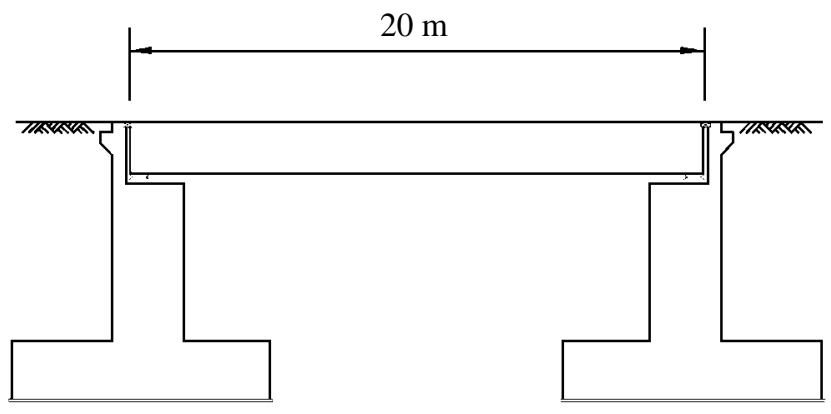

(a) Span arrangement

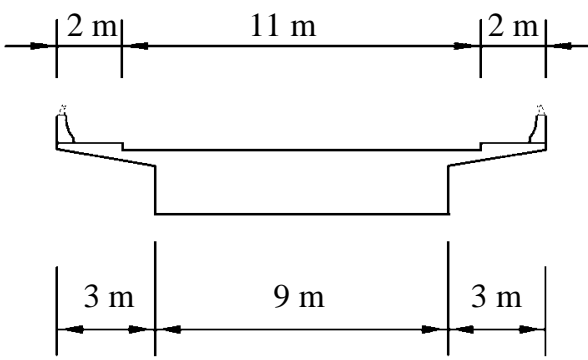

(b) Cross section

Fig. 6. RC bridge without stridden river.

Table 4. Construction cost of RC bridge without stridden river

\begin{tabular}{|c|c|c|c|c|c|}
\hline Component & $\begin{array}{c}\text { Construction } \\
\operatorname{cost}\left(\times 10^{3} \text { NTD }\right)\end{array}$ & Component & $\begin{array}{c}\text { Construction } \\
\operatorname{cost}\left(\times 10^{3} \mathrm{NTD}\right)\end{array}$ & Component & $\begin{array}{c}\text { Construction } \\
\text { cost }\left(\times 10^{3} \mathrm{NTD}\right)\end{array}$ \\
\hline $\begin{array}{l}\text { 1. Guide passage } \\
\text { road embankment }\end{array}$ & 200 & 8. Friction layer & 40 & 15.supporting mat & 60 \\
\hline $\begin{array}{l}\text { 2. Guide passage } \\
\text { protection fence }\end{array}$ & 70 & $\begin{array}{l}\text { 9. Drainage } \\
\text { appliance }\end{array}$ & 60 & 16. Seismic block & 50 \\
\hline 3. River channel & -- & $\begin{array}{l}\text { 10. Stone curb and } \\
\text { Pedestrian way }\end{array}$ & 50 & 17. Expansion Joint & 40 \\
\hline $\begin{array}{l}\text { 4. Guide passage } \\
\text { road embankment } \\
\text { protection }\end{array}$ & -- & $\begin{array}{l}\text { 11. Balustrade } \\
\text { protection fence }\end{array}$ & 60 & 18. Major member & 150 \\
\hline $\begin{array}{l}\text { 5. Abutment } \\
\text { foundation }\end{array}$ & 90 & $\begin{array}{l}\text { 12. Substructure } \\
\text { protection }\end{array}$ & 90 & 19. Minor member & 130 \\
\hline 6. Abutment & -- & 13. Pier foundation & 130 & 20. Deck & 80 \\
\hline 7. Wing masonry & -- & 14. Pier shaft & 100 & 21. Other & 70 \\
\hline
\end{tabular}


calculating every substructural weighting value, $w_{j 1}$, we obtain the results as listed in Table 6. Substituting these values into Eq. (6), we have $\xi=4.62, \theta=0.343, w=$ 6.837 , and $C_{0}=2211.406\left(\times 10^{3} \mathrm{NTD}\right)$.

Inserting the values of $w$ and $C_{0}$ into Eq. (7), we have

$$
C(\varphi)=2211.406\left[1-\frac{1}{6.837} \ln (1-\varphi)\right]\left(\times 10^{3} \mathrm{NTD}\right)
$$

The failure loss $D$ rises with $1 \%$ per year, we seek the value of failure loss, $D=2980.641$ ( $\times 10^{3}$ NTD). Substituting the value of $D$ into Eq. (3) and choosing its minimum, we have

$$
\begin{aligned}
W(\varphi) & =12211.406\left[1-\frac{1}{6.837} \ln (1-\varphi)\right] \\
& +2980.641(1-\varphi) \rightarrow \min
\end{aligned}
$$

That is, we get the minimum $W(\varphi)=3271.454(\times$ $10^{3}$ NTD) at $\varphi=0.89$ as shown in Figure 7.

\section{DISCUSSION}

From the system engineering point of view, the RC bridge with stridden river is a complicate structural system consisted of 21 substructures such as decks, beams, girders, bearings, piers and foundations etc. Accordingly, the damage evaluation is a synthetic evaluation process, which is started from the individual substructure to the whole bridges. Certainly, the optimum reliability of the whole bridge can not represent the reliability of each substructure. When the damaged RC bridge needs to be repaired, it is only necessary to repair all the substructures. From the two illustrative examples stated above, the RC bridge without stridden

\begin{tabular}{|c|c|c|c|c|c|}
\hline Component & $\begin{array}{l}\text { Weight } \\
\text { factor }(w)\end{array}$ & Component & $\begin{array}{l}\text { Weight } \\
\text { factor }(w)\end{array}$ & Component & $\begin{array}{l}\text { Weight } \\
\text { factor }(w)\end{array}$ \\
\hline $\begin{array}{l}\text { 1. Guide passage } \\
\text { road embankment }\end{array}$ & 3 & 8. Friction layer & 3 & 15. supporting mat & 5 \\
\hline $\begin{array}{l}\text { 2. Guide passage } \\
\text { protection fence }\end{array}$ & 2 & 9. Drainage appliance & 4 & 16. Seismic block & 5 \\
\hline 3. River channel & -- & $\begin{array}{l}\text { 10. Stone curb and } \\
\text { Pedestrian way }\end{array}$ & 2 & 17. Expansion Joint & 7 \\
\hline $\begin{array}{l}\text { 4. Guide passage } \\
\text { road embankment } \\
\text { protection }\end{array}$ & -- & $\begin{array}{l}\text { 11. Balustrade } \\
\text { protection fence }\end{array}$ & 3 & 18. Major member & 10 \\
\hline 5. Abutment foundation & 7 & $\begin{array}{l}\text { 12. Substructure } \\
\text { protection }\end{array}$ & 7 & 19. Minor member & 10 \\
\hline 6. Abutment & -- & 13. Pier foundation & 11 & 20. Deck & 10 \\
\hline 7. Wing masonry & -- & 14. Pier shaft & 11 & 21. Other & 1 \\
\hline
\end{tabular}
river has less evaluation items than the one with a

Table 5. Weighting values of the D.E.R. evaluation method for the composite component of RC bridge without stridden river

\begin{tabular}{|c|c|c|c|c|c|c|c|c|c|c|}
\hline Structural member $j$ & \multicolumn{2}{|c|}{12} & 15 & \multicolumn{2}{|c|}{13} & 16 & 14 & \multicolumn{2}{|c|}{20} & 17 \\
\hline$w_{j}$ & \multicolumn{2}{|c|}{7} & 5 & \multicolumn{2}{|c|}{11} & 5 & 11 & \multicolumn{2}{|c|}{10} & 7 \\
\hline$C_{0 j}\left(\times 10^{3} \mathrm{NTD}\right)$ & \multicolumn{2}{|c|}{90} & 60 & \multicolumn{2}{|c|}{130} & 50 & 100 & \multicolumn{2}{|c|}{80} & 40 \\
\hline$w_{j} / C_{0 j}$ & \multicolumn{2}{|c|}{0.078} & 0.083 & \multicolumn{2}{|c|}{0.084} & 0.100 & 0.110 & \multicolumn{2}{|c|}{0.125} & 0.175 \\
\hline$w_{j 1}$ & \multicolumn{2}{|c|}{0.18} & 0.17 & \multicolumn{2}{|c|}{0.17} & 0.14 & 0.13 & \multicolumn{2}{|c|}{0.11} & 0.08 \\
\hline Structural member $j$ & 21 & 2 & 1 & 10 & 11 & 9 & 18 & 8 & 19 & 5 \\
\hline$w_{j}$ & 1 & 2 & 3 & 2 & 3 & 4 & 10 & 3 & 9 & 7 \\
\hline$C_{0 j}\left(\times 10^{3} \mathrm{NTD}\right)$ & 70 & 70 & 100 & 50 & 60 & 60 & 150 & 40 & 130 & 90 \\
\hline$w_{j} / C_{0 j}$ & 0.014 & 0.029 & 0.030 & 0.040 & 0.050 & 0.067 & 0.067 & 0.075 & 0.077 & 0.078 \\
\hline$w_{j 1}$ & 1 & 0.48 & 0.47 & 0.35 & 0.28 & 0.21 & 0.21 & 0.19 & 0.18 & 0.18 \\
\hline
\end{tabular}

Table 6. Construction cost and weighting value for $\mathrm{RC}$ bridge without stridden river 
stridden river. So the increasing weighting values of some estimated items increase failure loss. Therefore, the best results will be obtained by increasing substructure items. There are several methods to estimate the service life of a RC bridge after repair. Liang et al. [8] used the net gross profit to predict service life after repair. The relative formula is

$$
\begin{aligned}
A\left(t_{r}\right) & =\left[\sum_{i=1}^{t_{r}} \frac{J_{i}}{(1+r)^{i}}-\frac{L_{t_{r}}}{(1+r)^{t_{r}}}-\left(L+C_{r}\right)\right]\left(A / P, r, t_{r}\right) \\
& \rightarrow \min
\end{aligned}
$$

where $A\left(t_{r}\right)$ is the net gross profit after $t_{r}$ years after repair, $L$ is the residual value of $\mathrm{RC}$ bridge while repairing, $L_{t_{r}}$ is the residual value of $\mathrm{RC}$ bridge continued use $t_{r}$ years after repair, and $J_{i}$ is the net profit value per year. $A=P\left[\frac{r(1+r)^{t} r}{(1+r)^{t} r-1}\right]$ is the conversion coefficient, $P$ is the present value and $A$ is the annual value.

Eq. (16) is used to find the net gross profit and service life using profit value and residual value. It calculates the value of $J_{i}$ combined the failure loss due to the whole possible occurrence of every year and miscellaneous expenses. If the evaluation is simplified then the excess subjective point of view will occur a larger different value.

Taking example 1 as an illustrative case and substituting $L=3000, L_{t_{r}}=2500$, and $C_{r}=5000$ into Eq.(16), in the sense that $A\left(t_{r}\right)=\left[\sum_{i=1}^{t_{r}} \frac{2000(1-0.03 i)}{(1+0.12)^{i}}-\right.$

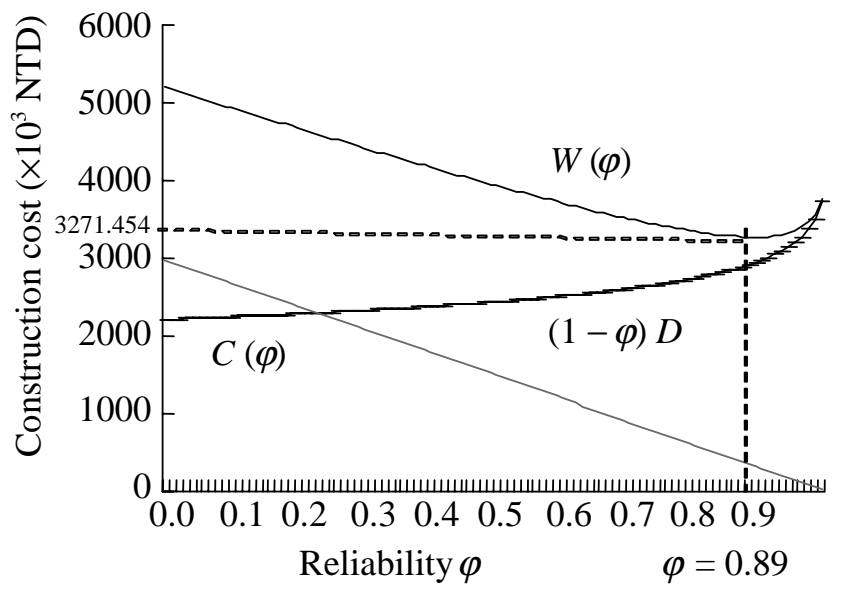

Fig. 7. Relationship between reliability and construction cost of RC bridge without stridden river after repair. $\left.\left.\frac{2500}{(1+0.12)^{t_{r}}}-(3000+5000)\right] \rightarrow\left(\frac{0.12(.12)^{t_{r}}}{(1.12)^{t}-1}\right]\right)$ max we obtain $A\left(t_{r}\right)=493.938\left(\times 10^{3}\right.$ NTD $)$ when $t_{r}=38$ years as shown in Figure 8. After compared Eq. (11) with Eq. (16), we know the exploration of failure loss, maintenance expenses, and reliability of Eq. (11) is an important key point. If one of failure losses, maintenance expenses, and reliability is eliminated, then we can not acquire the best accurate value. However, the judgment of failure loss should be achieved by professional engineers using professional knowledge. In this paper, we use the maximum expected value to judge the failure loss. Based on the proposed method, we obtain the optimum reliability for the whole RC bridge.

\section{CONCLUSION}

The relationship between reliability and engineering system construction cost and the optimization analysis of repair alternative have been described. The proposed method has been applied to obtaining the optimum reliability for existing RC bridges with and without stridden rivers according to the DER evaluation method. Some important results can be drawn as follows:

1. From the relationship between the reliability and engineering system construction cost of existing RC bridges with and without stridden rivers after repaired, the lowest cost is occurred due to the condition of the best reliability at optimum economy.

2. Base on the relationship between reliability and the construction cost, the expected profit value and the value of failure loss $D$ can be found to estimate the

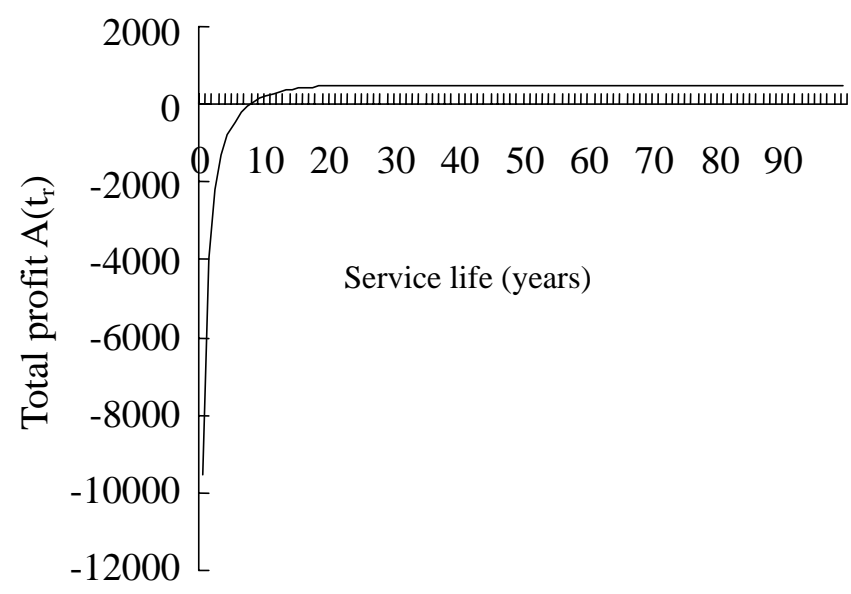

Fig. 8. Relationship between service life and total profit of $\mathrm{RC}$ bridge without stridden river after repair. 
optimum reliability of RC bridge.

3. Utilizing the optimum reliability in the previous approach and the damaged condition, the repair cost can be estimated. Considering the capital interest rate and the repair expenses, the service life for taking advantage of the next repair time can be sought.

4. Through the explanation of the given examples, the repair cost of the RC bridge is quite huge. Each weighting value will influence the whole profit value. It is obviously needed to assess in detail in order to get the best result.

5. The evaluated procedure of this investigation can be powerfully used by the engineering decision-makings of repair not only for the existing $\mathrm{RC}$ structures stated above but also for the other RC structures.

\section{APPENDIX A: DERIVATION OF SOME FORMULAS}

The key point of whole optimization problem of solving multiple grade engineering system is to establish the function between construction cost, $C$, and reliability, $\varphi$, of the system. Since both the $C$ and $\varphi$ do not exist one-to-one corresponding relation, first we provide two equivalent definitions (mutual dual):

1. Given $\varphi, C$ is the corresponding minimum construction cost. Under this situation, $\varphi$ should be satisfied the following equation [19].

$$
\varphi=\varphi_{1}^{J} \prod_{j=2}^{J} \frac{1}{w_{j 1}+\left(1-w_{j 1}\right) \varphi_{1}}
$$

where $\varphi_{1}$ is the reliability of the first subsystem,

$$
w_{j 1}=\frac{C_{0 j} w_{1}}{C_{01} w_{j}}=\frac{\frac{w_{1}}{C_{01}}}{\frac{w_{j}}{C_{0 j}}}
$$

where $w_{j}$ and $C_{0 j}$ are the parameters of relationships between construction cost and reliability of the $j$-th subsystem.

2. Given $C, \varphi$ is the corresponding maximum reliability. Below this condition,

$$
e^{-\frac{w_{1}}{C_{01}}\left(C-\sum_{j=1}^{L} C_{0 j}\right)}=\varphi_{1} \prod_{j=2}^{J}\left[\frac{\varphi_{1}}{b_{j 1}+\left(1-b_{j 1}\right) \varphi_{1}}\right]^{W_{j 1}}
$$

where $\varphi_{1}=1-\varphi, b_{j 1}=\frac{1}{w_{j 1}}$.

In order to find the relation between $C$ and $\varphi$ of the whole system, we may combine Eqs. (A-1) and (A2) for eliminating $\varphi_{1}$. We first begin from Eq. (A-1) as follows. Because $w_{j 1}+\left(1-w_{j 1}\right) \varphi_{1}=1-\left(1-w_{j 1}\right)(1-$ $\varphi_{1}$ ), Eq. (A-1) can be rewritten as

$$
\varphi=\varphi_{1}^{J} \prod_{j=2}^{J} \frac{1}{1-\left(1-w_{j 1}\right)\left(1-\varphi_{1}\right)}
$$

Owing to $w_{j 1}=\frac{w_{1} / C_{01}}{w_{j} / C_{0}}$, if take

$$
\frac{w_{1}}{C_{01}}=\min _{j}\left(\frac{w_{j}}{C_{0 j}}\right)
$$

then $0<w_{j 1} \leq 1(j=2,3, \ldots, J)$. Further, the probability of failure loss $1-\varphi_{1}$ is less than 1 . From Eq. (A-3), we know that $\left|\left(1-w_{j 1}\right)\left(1-\varphi_{1}\right)\right| \ll<1$.

We also know that when $|\beta|<1$, we have

$$
\frac{1}{1 \pm \beta}=1 \mp \beta \pm \beta^{2} \mp \cdots
$$

and

$$
\prod_{i=1}^{n}\left(1+\beta_{i}\right)=1 \mp \sum_{i=1}^{n} \beta_{i}+\sum_{i \neq k} \beta_{i} \beta_{k}
$$
we obtain

When $|\beta|<<$ and neglect the higher degree terms,

$$
\frac{1}{1 \pm \beta} \approx 1 \mp \beta
$$

and

$$
\prod_{i=1}^{n}\left(1 \pm \beta_{i}\right) \approx 1 \pm \sum_{i=1}^{n} \beta_{i}
$$

From Eqs. (A-3), (A-4), (A-7) and (A-8), we may get the approximate

$$
\begin{aligned}
& \varphi \approx \varphi_{1}^{J} \prod_{j=2}^{J}\left[1+\left(1-w_{j 1}\right)\left(1-\varphi_{1}\right)\right] \\
& \approx \varphi_{1}^{J}\left[1+\left(1-\varphi_{1}\right) \prod_{j=2}^{J}\left(1-w_{j 1}\right)\right]
\end{aligned}
$$

From Eq. (A-9), we have the root of $J$-degree

$$
\varphi^{\frac{1}{J}} \approx \varphi_{1}\left[1+\left(1-\varphi_{1}\right) \sum\left(1-w_{j 1}\right)\right]^{\frac{1}{J}}
$$

We know the approximate of one degree

$$
(1+\beta)^{\alpha} \approx 1+\alpha \beta
$$

When $|\alpha \beta| \ll<1$, there is a good approximation. After the development of multiple formula of square brackets in the right-hand side of Eq. (A-10), we have

$$
\left(1-\varphi_{1}\right) \frac{1}{J} \sum_{j=2}^{J}\left(1-w_{j 1}\right)<\left(1-\varphi_{1}\right)<<1
$$

Hence, from Eq. (A-10), we obtain the approximate 
$\varphi^{\frac{1}{J}}=\varphi_{1}\left[1+\left(1-\varphi_{1}\right) \frac{1}{J} \sum_{j=2}^{J}\left(1-w_{j 1}\right)\right]$

Solving Eq. (A-13), we have

$$
\varphi_{1}=\frac{(1+A) \pm \sqrt{1+A^{2}-4 A \varphi^{\frac{1}{J}}}}{2 A}
$$

where

$$
A=\frac{1}{J} \sum_{j=2}^{J}\left(1-w_{j 1}\right)
$$

Since the radical value in the right-hand side of Eq. (A-14) is larger than (1-A), and the value of $\varphi_{1}$ is less than 1 , we obtain the effective solution

$$
\varphi_{1}=\frac{(1+A)-\sqrt{1+A^{2}-4 A \varphi^{\frac{1}{J}}}}{2 A}
$$

Now we turn to discuss Eq. (A-2). Pay attention to $b_{j 1}=\frac{1}{w_{j 1}}$ and $w_{11}=1$, Eq. $(\mathrm{A}-2)$ becomes

$$
e^{-\frac{w_{1}}{C_{01}}\left(C-\sum_{j=1}^{\left.\sum_{1} C_{0 j}\right)}\right.}=\varphi_{1}\left(\sum_{j=1}^{J} w_{j 1}\right)\left(\prod_{j=1}^{J} w_{j 1}{ }^{w_{j 1}}\right) F\left(\varphi_{1}\right)
$$

where $F\left(\varphi_{1}\right)=\prod_{j=1}^{J}\left(\frac{1}{1-\left(1-w_{j 1}\right) \varphi_{1}}\right)^{w_{j 1}}$

Using the approximate formulas, i.e. Eqs. (A-7), (A-8) and (A-11), we obtain

$$
\begin{aligned}
F\left(\varphi_{1}\right) & \approx \prod_{j=1}^{J}\left[1+\left(1-w_{j 1}\right) \varphi_{1}\right]^{w_{j 1}} \\
& \approx \prod_{j=1}^{J}\left[1+w_{j 1}\left(1-w_{j 1}\right) \varphi_{1}\right] \\
& \approx 1+\sum_{j=1}^{J} w_{j 1}\left(1-w_{j 1}\right) \varphi_{1}
\end{aligned}
$$

Substituting Eq. (A-18) into Eq. (A-17) and letting

$$
\begin{aligned}
& \xi=1+\sum_{j=2}^{J} w_{j 1}=\sum_{j=1}^{J} w_{j 1}, w_{11}=1 \\
& \theta=\left(\prod_{j=1}^{J} w_{j 1} w_{j 1}\right)^{\frac{1}{\xi}}
\end{aligned}
$$

We have

$$
e^{-\frac{w_{1}}{C_{01} \xi}\left(C-\sum_{j=1}^{J} C_{0 j}\right)}=\varphi_{1} \theta\left[F\left(\varphi_{1}\right)\right]^{\frac{1}{\xi}}
$$

Using Eq. (A-11), we have

$$
\left[F\left(\varphi_{1}\right)\right]^{\frac{1}{\xi}} \approx 1+\frac{1}{\xi} \varphi_{1} \sum_{j=1}^{J} w_{j 1}\left(1-w_{j 1}\right)
$$

$$
\begin{aligned}
& \text { Let } \zeta=\frac{1}{\xi} \sum_{j=1}^{J} w_{j 1}\left(1-w_{j 1}\right) \\
& \text { and } \eta=e^{-\frac{w_{1}}{C_{01} \xi}\left(C-\sum_{j=1}^{\infty} C_{0 j}\right)}
\end{aligned}
$$

The substitution of Eqs. (A-23) and (A-24) into Eq. (A-16) yields

$$
\varphi_{1} \theta\left(1-\xi \varphi_{1}\right)=\eta
$$

Solving Eq. (A-25) for getting effective root

$$
\varphi_{1}=\frac{-1+\sqrt{1+4 \frac{3 \eta}{\theta}}}{23}=\frac{\eta}{\theta}
$$

From Eqs. (A-11) and (A-26), we obtain the approximate formula

$$
\begin{gathered}
(1+A)-\sqrt{(1+A)^{2}-4 A \varphi^{\frac{1}{J}}}=2 A\left(1-\frac{\eta}{\theta}\right) \\
\text { or }(1-A)+\frac{2 A}{\theta} \eta=\sqrt{(1+A)^{2}-4 A \varphi^{\frac{1}{J}}}
\end{gathered}
$$

If ignore the small term of $\eta^{2}$, then Eq. (A-27) or Eq. (A-28) becomes

$$
\varphi^{\frac{1}{J}}=1-\frac{1-A}{\theta} \eta
$$

Eq. (A-29) is rewritten as

$$
\varphi=\left[1-\frac{1-A}{\theta} \eta\right]^{J} \approx 1-\frac{J(1-A)}{\theta} \eta
$$

Substituting Eq. (A-24) into Eq. (A-30) and paying attention to $J(1-A)=\xi$, we have the approximate formula between $\varphi$ and $C$.

$$
\varphi=1-\exp \left[-\frac{w_{1}}{C_{01} \xi}\left(C-\sum_{j=1}^{J} C_{0 j}\right)+\ln \frac{\xi}{\theta}\right]
$$

Eq. (A-31) may write the same form, $\varphi_{j}\left(C_{j}\right)$ of the subsystem, i.e.,

$$
\varphi(C)=1-e^{-w\left(\frac{C}{C_{0}}-1\right)}
$$

where

$$
w=\frac{w_{1}}{C_{01} \xi} \sum_{j=1}^{J} C_{0 j}+\ln \frac{\xi}{\theta}
$$

$C_{0}=\frac{C_{01} \xi}{w_{1}} w$

$$
\frac{w_{1}}{C_{0}}=\underset{j=1}{J}\left(\frac{w_{j}}{C_{0 j}}\right)
$$

$\xi=\sum_{j=1}^{J} w_{j 1}$ 


$$
\begin{gathered}
\theta=\left(\prod_{j=1}^{J} w_{j 1} w_{j 1}\right)^{\frac{1}{\xi}} \\
w_{j 1}=\frac{\frac{w_{1}}{C_{01}}}{\frac{w_{j}}{C_{0 j}}}
\end{gathered}
$$

\section{REFERENCES}

1. Al-Hajj, A., "Modeling Running and Maintenance Costs for Life Cycle Costing Applications in Buildings," Durability Build. Mat. Comp., Vol. 8, pp. 1699-1706 (1999).

2. Cheung, M.S. and Kyle, B.R., "Service Life Prediction of Concrete Structures by Reliability Analysis," Constr. Build. Mater., Vol. 10, No. 1, pp. $45-55$ (1996).

3. CSIR, Taiwan Area National Freeway Bureau Bridge Management System, Description of Modulus and Computer Options, Pretoria, South Africa, pp. 47 (1994).

4. Frangopol, D.M., Bridge Safety and Reliability, ASCE, pp. 852-869 (1999).

5. Frangopol, D.M. and Furuta, H., Life-cycle Cost Analysis and Design of Civil Infrastructure Systems, ASCE, pp. 1210-1224 (2001).

6. Imai, K. and Frangopol, D.M., "System Reliability of Suspension Bridges," Struct. Saf., Vol. 24, No. 2-4, pp. 219-259 (2002).

7. Kleinfeld, I.H., Engineering Economics: Analysis for Evaluation of Alternatives, International Thomson Publishing Asia, Singapore, (1994).

8. Liang, M.T., Huang, R., Chen, J.T., Liang C.H., Chen, G.S., and Liao, Y.S., Characteristic of Deteriorating and Service Life of Reinforced Concrete Research Report, Sinotech Engineering Consultants, Inc. (1998). (in Chinese)
9. Liang, M.T., Lin, C.M., and Yeh, C.J., "Comparison Matrix Method and Its Applications to Damage Evaluation for Existing Reinforced Concrete Bridges," J. Mar. Sci. Technol., Vol. 11, No. 2, pp. 70-82 (2003).

10. Liang, M.T. and Lan, J.J., "Reliability Analysis of an Existing Reinforced Concrete wharf Laden in a Chloride Environment," J. Chin. Inst. Eng., Vol. 26, No. 5, pp. 647-658 (2003).

11. Liang, M.T. and Lan, J.J., "Reliability Analysis for the Existing Reinforced Concrete Pile Corrosion of Bridge Substructure," Cement Concrete Res., Vol. 35, pp. 540550 (2005).

12. Liang, M.T., Chen, S., Lee, C.W., and Yeh, C.J., "Application of Fuzzy Optimum System Hierarchy Analysis Selection Method to Determining Repair Order for Existing Reinforced Concrete Bridges," J. Chin. Inst. Eng., Vol. 28, No. 2, pp. 189-204 (2005).

13. Mohammadi, J. and Guralnick, A., "Incorporation Lifecycle Costs in Highway-bridge Planning and Design," $J$. Transp. Eng., ASCE, Vol. 121, No. 5 pp. 417-424 (1995).

14. Moses, F., "Structural System Reliability and Optimization," Comput. Struct., Vol. 7, No. 2, pp. 283-290 (1977).

15. Sexsmitha, R.G. and Reidb, S.G., "Safety Factors for Bridge Falsework by Risk Management," Struct. Saf., Vol.25, pp. 227-243 (2003).

16. Steiner, H.M., Engineering Economic Principles, Mcgraw-will Inc., New York (1996).

17. Van, S.W. and Liou, S.B., Architectural Engineering Technical Economy, Chinese Architectural Industry Publisher, Beijing, China (1998). (in Chinese)

18. Wang, G.Y., "The Exploration of Theory of Decision for the Maintenance and Repair of Structures," J. Harb. Arch. Civil Eng. Inst., Vol. 23, No. 2, pp. 1-9 (1990). (in Chinese)

19. Wang, G.Y., Theory of Software Engineering Design, Science Publisher, Beijing, China (1992). (in Chinese) 